\title{
Gerencialismo, Internacionalização da educa- ção e o papel da Teach For All no Brasil
}

Maria Raquel Caetano Instituto Federal de Educação, Ciência e Tecnologia Sul-Rio-Grandense Marilda de Oliveira Costa Universidade do Estado do Mato Grosso

\section{Resumo}

Oartigo examina os avanços da privatização da política educacional na proposta de formação de professores através da ONG "Ensina Brasil" na educação pública brasileira, em especial, na rede estadual de ensino de Mato Grosso. Trata-se da versão brasileira da organização global Teach For All responsável pela internacionalização da ONG Teach For America. Para a análise, utilizaram-se referenciais que abordam a internacionalização de políticas educacionais, o gerencialismo e as mais recentes alterações do capitalismo global, autointitulado capitalismo social. Para tanto, utilizou-se um método que entrecruza dados coletados em sites da web e dados documentais confrontados com discursos e motivações dos principais atores, público e privado, envolvidos nas negociações e o papel reservado a cada sujeito nesse processo. Os resultados apontam para novos desenhos de políticas globais para a educação, fomentada por organizações sociais do grande capital. A educação deixa de ser um direito e torna-se objeto de caridade aos mais pobres ou mesmo um negócio.

Palavras-chave: Gestão. Privatização. Professores. Democratização.

\section{Managerialism, internationalization of education and the role of Teach for All in Brazil}

\begin{abstract}
The article examines the advances of the privatization of educational policy in the proposal of teacher education through the NGO "Teaches Brazil" in Brazilian public education, especially in the state educational network of Mato Grosso. This is the Brazilian version of the global Teach For All organization responsible for the internationalization of the NGO Teach For America. For the analysis, we used reference that addresses the internationalization of educational policies, managerialism and the latest changes in global capitalism, self-proclaimed social capitalism. For this, we used a method that crosses data collected in websites and documentary data confronted with speeches and motivation of the main authors, public and private, involved in the negotiations and the role reserved to each individual in this process. The results point to new designs of global policies for education, fostered by social organizations of big capital. Education ceases to be a right and becomes the object of charity to the poorest or even a business.
\end{abstract}

Keywords: Management. Privatization. Teachers. Democratization. 
Gerencialismo, Internacionalização da educação e o papel da Teach for all no Brasil

\section{Gerencialismo, Internacionalización de la educación y el papel de Teach For All em Brasil}

\section{Resumen}

El artículo examina los avances de la privatización de la política educativa en la propuesta de formación de profesores a través de la ONG "Ensina Brasil" en la educación pública brasileña, en especial en la red estatal de enseñanza de Mato Grosso. Se trata de la versión brasileña de la organización global Teach For All responsable de la internacionalización de la ONG Teach For America. Para el análisis, se utilizaron referenciales que abordan la internacionalización de políticas educativas, el gerencialismo y las más recientes alteraciones del capitalismo global, autointitulado capitalismo social. Para ello, se utilizó un método que entrecruza datos recolectados en sitios web y datos documentales confrontados con discursos y motivaciones de los principales actores, público y privado, involucrados en las negociaciones y el papel reservado a cada sujeto en ese proceso. Los resultados apuntan a nuevos diseños de políticas globales para la educación, fomentada por organizaciones sociales del gran capital. La educación deja de ser un derecho y se convierte en objeto de caridad a los más pobres o incluso a un negocio.

Palabras clave: Gestión. La privatización. Profesores. Democratización.

\section{Introdução}

A existência de uma agenda globalmente estruturada para a educação (DALE, 2004; ANTUNES, 2008), materializa-se como empréstimo, convergência e transferência de políticas, e se acomodam às especificidades históricas e culturais de cada país. Aspectos dessa agenda podem ser facilmente identificados a partir da avaliação padronizada como movimento político global (SMITH, 20 16) e, nessa perspectiva, a avaliação é considerada instrumento privilegiado para promover as reformas dos sistemas educativos. Complementarmente, não tem sido poucas as iniciativas de uma variedade de entidades, fundações, organizações sociais (OS) "empenhadas" em resolver os problemas educacionais, especialmente relacionados à qualidade, apontados em resultados dessas mesmas avaliações que subliminarmente, responsabiliza o professor pela eficiência e eficácia do sistema educacional. Entre os atores envolvidos em iniciativas globais, encontra-se a Teach For All que atua em mais de 45 países de todos os continentes, incluindo o Brasil, por meio do Ensina Brasil. A Teach For All, apresentada na sequência deste texto, é a responsável pela internacionalização da Teach For América, entidade que atua há mais 
20 anos na área educacional nos Estados Unidos, por meio de recrutamento e treinamento em cinco semanas, de jovens universitários para atuar em escolas públicas, por um período de dois anos, subtraindo do professor a especificidade do trabalho docente.

A criação, expansão e atuação de entidades como a Teach For All, situam-se no contexto de reformas do Estado e da educação, do avanço acelerado das novas tecnologias de informação e comunicação a partir do último quarto do século XX, que deu novo impulso à globalização econômico-financeira e cultural, em "tempos de crise estrutural de acumulação do capital" (MĖSZÁROS, 2009). Nesse contexto, a atuação da Teach For All é parte constituitiva das reformas educacionais em curso.

Medidas para conter a crise e possibilitar a expansão, concentração e acúmulo de capital, em especial o rentista, improdutivo (BRENNER, 2003), desenvolveu-se aceleradamente e com ela duras críticas à democracia liberal burguesa e ao próprio Estado Capitalista (OFFE, 1984). A forma do Estado socialdemocrata nos países centrais, em vigor desde o pós-Segunda Guerra Mundial, foi seriamente atacada pela emergência de novas narrativas como o discurso neoliberal e conservador, aglutinado em torno de uma "Nova Direita". Com um discurso radicalmente favorável à hegemonia do mercado em detrimento de direitos sociais e do Estado com funções empresariais, produtivas, articuladoras entre capital e trabalho, essa tendência político-ideológica orientou sucessivas reformas ao longo das décadas de 1980, 1990 e mais recentemente com a promoção dos famigerados "ajustes fiscais" promovido pelos Estados. Se a primeira onda de reformas foi protagonizada, inicialmente, pelo Partido Conservador na Inglaterra e por Republicanos, nos Estados Unidos, a segunda onda mostra que nem mesmo os partidos Trabalhistas não conseguiram escapar da lógica impositiva do capital sobre o trabalho, tal como mostra - New Labor, na Inglaterra, o Australian Labor Party, ALP, na Austrália, New Zealand Labour Party, da Nova Zelândia, o Partido dos Trabalhadores, no Brasil, só pra citar alguns Pode-se considerar que essas últimas reformas, orientadas por uma Terceira Via (GIDDENS, 2001), não romperam com os preceitos neoliberais em curso. Segundo Peroni, o "neoliberalismo e a Terceira Via são os mesmos e diferentes. Eles são diferentes tipos de combinações policy". A Terceira Via 
Gerencialismo, Internacionalização da educação e o papel da Teach for all no Brasil

[... não seria possível sem o neoliberalismo, mas difere em aspectos importantes em termos do papel do Estado e suas relações com os setores público e privado, entre outras coisas (PERONI, 2007, p. 201.

Influenciado por essas reformas, o Brasil também incluiu-se na sanha reformista, ainda no início dos anos 1990, no governo Collor de Melo, do Partido Republicano (PR), cuja continuidade e aprofundamento deram-se com - governo de Fernando Henrique Cardoso do Partido da Social Democracia (PSDB), a partir da segunda metade da década de 1990. Sem romper com os princípios neoliberais de reforma do Estado e da educação, os governos do Partido dos Trabalhadores (PT), com Luís Inácio Lula da Silva (2003 a 2006; 2007 a 2010) e Dilma Vana Housseff (2011 a 2014; 2015)’ pautaram suas políticas no crescimento econômico com distribuição de renda, ou seja, em consonância com o neodesenvolvimentismo latino-americano, que visava amenizar o desastre econômico e social causado pelas reformas neoliberais no continente. $\bigcirc$ neodesenvolvimentismo ${ }^{2}$ é considerado como nova concepção de desenvolvimento que tem, como princípio, aliar crescimento econômico com o combate à pobreza, o desenvolvimento humano e a sustentabilidade.

$\bigcirc$ rastro das reformas da qual emergiu novas e complexas formas de reestruturação do Estado e da educação, no Brasil, não desapareceu no período subsequente às reformas neoliberais, ficou menos visível em razão da política neodesenvolvimentista dos governos do PT. Se, de um lado, ampliou, garantiu e implementou inúmeros direitos sociais e a inserção do país na economia global; por outro lado, os governos do PT não tiveram força suficiente para neutralizar o avanço de movimentos dos reformadores empresariais na educação. As políticas continuaram com um viés mercadológico, influenciadas por princípios de competição, meritocracia e responsabilização típicos da organização e gestão empresariais, portanto, extraídas do mercado, transpostas e adaptadas ao meio educacional cujas mudanças mais visíveis manifestam-se por meio de diferentes arranjos, entre eles o público-privado que levam à privatização da educação, conforme adverte Lima (2013).

Nesse contexto, as Organizações Não-Governamentais ganharam relevância, protagonizando o que pode ser considerado uma verdadeira "Revolução Copernicana" na educação pública. Tais mudanças abrangem o próprio conteúdo da educação manifestamente por meio de áreas como o currículo, a avaliação, o planejamento e a gestão, a carreira docente, os 
princípios, direitos e responsabilidades do Poder Público em assegurar o direito à educação com gestão pública, garantia de acesso, permanência e terminalidade da escolarização de crianças e jovens, com qualidade socialmente referenciada, ou seja, com qualidade científica, pedagógica e democrática.

A reforma gerencial foi um movimento mundial em intensidades diferentes, mas marcada, predominantemente, por conceitos comuns, como valorização das funções gerenciais na administração pública, controle de resultados, autonomia de gestão, responsabilidade individual na prestação de serviços públicos baseados em metas de desempenho, desenvolvimento de instrumentos que visam à eficiência e à eficácia na gestão, avaliação dos programas e medidas de incentivos aos administradores para melhorar a gestão (PEREIRA, 1998). No Brasil, o gerencialismo ganha materialidade mais expressiva a partir da Reforma do Estado (1995-1999), quando Bresser-Pereira implanta o Plano Diretor da Reforma do Aparelho do Estado.

$\bigcirc$ alargamento da reforma gerencial estendeu-se aos entes federados e o estado de Mato Grosso não ficou imune às influências da tendência gerencialista na educação básica mato-grossense. Essa tendência tem seus antecedentes nos anos 1990, com iniciativas governamentais voltadas para diferentes formas de arranjos institucionais, tanto com o Ministério da Educação e o Banco Mundial, quanto com entidades do setor privado, por meio de parcerias e contratos de gestão, consultorias, compra de materiais apostilados, assim como por iniciativa própria, em aparente tensão com os princípios formais da gestão democrática, também instituídos no mesmo período (MATO GROSSO, 1998). Destaca-se a parceria da Secretaria de Estado da Educação (SEDUC) com o Ensina Brasil, firmada por meio do Consórcio Brasil Central lassociação pública formada por cinco Estados do Norte, Centro-Oeste e o Distrito Federal que atua em várias áreas) com a Teach For All, no ano de 2016 (MATO GROSSO,2016). Documentos publicados tanto no Diário Oficial de Mato Grosso, como na página oficial da SEDUC e jornais da capital (Mídia News, 2017) dão conta que o convênio entrou em vigor a partir de 2017, com 35 "Ensinas"

Este texto apresenta resultados parciais de uma pesquisa realizada com o objetivo de analisar os avanços denominados de privatização da política educacional na proposta de formação de professores que vem sendo implantada, recentemente, na educação pública do estado de Mato Grosso por uma instituição que se apresenta como Organização Social e que integra 
uma rede global, a Teach For All. Para responder a esse objetivo, o artigo foi dividido em três seções: Gerencialismo e perspectivas atuais do capitalismo para as políticas educacionais, em que são apresentadas as atuais políticas educacionais como parte das redefinições do papel do Estado que alteram a gestão pública, gestão da educação e da escola com concepções gerencialistas em que o modelo gerencial possibilita que o Estado crie condições para o aumento dos investimentos privados na educação pública. A recorrência de parcerias público-privadas no Sistema Estadual de Educação de Mato Grosso e indicativos de hegemonia gerencialista em educação é a subseção em que se expões as mudanças ocorridas na gestão da educação no estado do Mato Grosso através da implantação de projetos e programas como parte das reformas apresentadas como modernizadoras que vem alterando a lógica de gestão democrática construída pelos professores historicamente para a gestão por resultados, incluindo a formação de professores. Na terceira seção, a Rede Teach For All, o Programa Ensina Brasil ou terceirizando a formação do professor em que se discorre sobre a rede global que busca direcionar a política de formação de professores implantada na rede estadual de ensino do Mato Grosso. Ao final, têm-se algumas considerações sobre a relação entre

254 as reformas gerenciais, as recentes estratégias de reorganização do capital global e as incursões de atores sociais globais, ativistas de uma "nova filantropia" e que vem delineando políticas globais de educação, cujas escola e educação pobres são voltadas para regiões e países mais pobres do globo. Considera-se, ainda, que a presença do Estado é indispensável pela organização, colaboração, articulação e atuação direta com outras esferas de governo e sociedade na elaboração, organização, gestão e financiamento da educação.

\section{Gerencialismo e perspectivas atuais do capitalismo para as políticas educacionais}

A política educacional é parte constitutiva das mudanças que vêm ocorrendo na redefinição do papel do Estado, com base nas múltiplas relações com o contexto histórico, político e social. Essas redefinições fazem parte de um contexto mais amplo, inseridos na crise do capital (PERONI, 2015; CAETANO, 2015). Concorda-se com Mészáros (2002) que o capitalismo foi construído ao 
longo de um processo histórico que evoluiu de maneira incontrolável e se torna um controle totalizante, na medida em que todos os seres humanos devem se ajustar a ele com o risco de não sobreviverem. A característica de "[...] engolir a tudo e a todos the concede o caráter de dinamismo que, por sua vez, conduz à ineficácia qualquer tentativa de controle" (MÉSZÁROS, 2002, p. 72).

No processo que se desdobra como consequência das formas contemporâneas de avanço do capital e, entre elas, como parte das políticas neoliberais, estão as reformas da gestão pública, introdução da gestão gerencial como uma política que traz alterações ao Estado, à sociedade e à educação. Ao fazer a crítica, Clarke e Newman (1997) apresentam o gerencialismo como a concepção que produz um Estado mais capaz de cumprir suas funções através de três aspectos centrais: economia, eficiência e efetividade e deveriam ser alcançados principalmente através da incorporação da lógica do mercado - entendida como superior à lógica do público - e de uma maior disciplina no serviço público para o oferecimento de serviços com melhor custo-benefício, o que seria garantido pela liberdade para gerenciar.

É nesse contexto que as reformas instituídas a partir dos anos 90 do século passado e que se aprofundam até os dias atuais, instauraram a "administração pública gerencial", que alterou o modelo de gestão pública, consequentemente, da gestão da educação e da escola, implantando a cultura gerencial.

Na educação, as mudanças têm operado através do Terceiro Setor, estratégia utilizada pela Terceira Via para materializar o projeto do capital. Peroni(2008) destaca que as teorias Neoliberal e Terceira Via têm em comum o diagnóstico da crise do capital, de que o culpado é o Estado, mas propõem estratégias diferentes de superação. "Nos dois, o Estado não é mais o responsável pela execução das políticas sociais: um repassa para o mercado e o outro para a chamada sociedade civil" (PERONI, 2008, p. 2).

Atualmente no Brasil, após o processo de impeachment da presidente Dilma Roussef, a radicalização do projeto liberal, derrotado nas últimas quatro eleições, vem levando ao extremo a reforma do Estado iniciada nos anos de 1990. "O objetivo é 'privatizar tudo o que for possível', tanto na infraestrutura econômica quanto na infraestrutura social" (FAGNANI, 2017, p. 11). Estudos realizados pelo autor apontam a destruição do sistema social do país como: "[...] o novo regime fiscal, o fim de vinculações de recursos para a área social; 
a reforma da previdência social; a reforma tributária e os retrocessos nos direitos trabalhistas e sindicais [...]" (FAGNANI, 2017, p. 11 ) o que apresenta sérios riscos e retrocessos às políticas sociais e aos trabalhadores.

No contexto atual de redefinição do papel do Estado, ganham força as estratégias de privatização do público e das parcerias com o terceiro setor mercantil como fundações, institutos ligados a empresas do mercado. A inserção da gestão privada na educação como proposta de melhoria da qualidade e as políticas nacionais que viabilizam a reprodução do capital pela educação como mercadoria, integram a lógica gerencial das reformas. Essas iniciativas alteram a lógica de gestão do público apresentando o mercado como parâmetro de qualidade e apresenta como centralidade a ampliação da esfera denominada de pública não estatal ou seja, a ampliação dos mecanismos de mercado no interior do público para que o Estado possa dividir e/ou repassar as responsabilidades e ações para o setor privado.

A lógica do mercado que, antes, era limitada na educação, passa agora a se constituir num mercado em ascensão em nível global com a introdução de mecanismos mercantis no interior da educação pública. Como defendeu Porter (1993) a educação é elevada à categoria mercantil para pro256 mover a "vantagem competitiva das nações". Nesse sentido,

Não é mais possível ver as políticas educacionais apenas do ponto de vista do Estado-nação: a educação é um assunto de políticas regional e global e cada vez mais um assunto de comércio internacional. A educação é, em vários sentidos, uma oportunidade de negócios (BALL, 2014, p. 1 108).

$\bigcirc$ modelo gerencial possibilita que o Estado crie condições para o aumento dos investimentos privados na educação pública. As experiências, introduzidas pela Nova Gestão Pública, representam uma múltipla e diversificada experiência teórica e aplicada, com variadas ênfases e formatos, na renovação da gestão nos Estados:

Não há dúvida de que o gerencialismo tornou-se algo como um modelo global para reforma, em relação ao qual, noções de desenvolvimento ou subdesenvolvimento de estados eram avaliadas, alimentando um extenso mercado para importação de habilidades e modelos do Reino Unido, EUA e Nova Zelândia e para expansão de consultorias em gestão que embrulhavam modelos de negócios 
e modelos de reforma e os comercializavam através de fronteiras nacionais (NEWMAN; CLARKE, 2012, p. 355-356).

As reformas no Brasil e no contexto latino-americano vêm ocorrendo sob o ideário do Neoliberalismo e da Terceira Via, mas também nos últimos anos como um movimento articulado de ideias liberais em ascensão, influenciadas por grandes corporações norte-americanas que vêm financiando e apoiando institutos, fundações e diferentes movimentos liberais. Esses movimentos, em escala global, são articulados especialmente por corporações internacionais como Atlas Network, Bill e Melinda Gates Foudation, Cato Institute, Koch Foudation entre muitos outros.

Desde a década de 90 do século passado, a educação é considerada um serviço não exclusivo do Estado, podendo transformar-se em organização social (OS) recebedora de recursos do orçamento público, tornando-se organizações públicas não estatais (BRASIL, 1995). Atualmente, as Organizações Sociais, a terceirização, as parcerias, vêm sendo implantadas na educação pública em vários estados brasileiros como é o caso recente dos estados de Goiás, Mato Grosso, Santa Catarina, Espirito Santo e Pará.

No contexto brasileiro, o repasse das políticas sociais ao Terceiro Setor denominado de terceiro setor mercantil (PERONI, 2013) é uma das estratégias utilizadas pelo Estado que abre espaço para atuação das instituições não estatais, como ONGs, fundações, institutos e mais recentemente através das OS - Organizações Sociais, atuando fortemente na terceirização dos serviços sociais. Essas instituições, por vezes, assumem o papel do Estado na elaboração de políticas, execução de programas, projetos e ações, e o Estado passa a ser um importante criador de mercados na área educacional. Nesse cenário, torna-se cada vez mais crescente a tendência dos governos de introduzir formas de privatização na educação pública ou em setores da educação pública através dos novos filantropos que vêm operando em nível global esperando retorno de suas doações. "Os novos filantropos querem ver impactos e resultados claros e mensuráveis de seus investimentos de tempo e dinheiro" (BALL, 2014, p. 122). Não há tempo a perder, os resultados são importantes para as avaliações, rankings e as evidências baseadas em indicadores de desempenho.

Outra forma de participação do setor privado, nos processos de tomada de decisão, é a privatização da política que ocorre "através de ideias 
e produção de textos da política por empresas educacionais e consultorias para e no interior do Estado através de assessorias, consultorias, recomendações" (BALL, 2014, p. 162 e 163 ou seja, "[...] os governos compram o conhecimento de política [...]"e a política transformada em mercadoria. Discursivamente, "[...] a participação do privado está se firmando rapidamente como um melhor caminho (the one best way) para pensar a respeito da futura cessão do setor público" (BALL, 2014, p. 162).

Essas iniciativas vêm ocorrendo através da constituição de redes globais com especial participação do setor privado. No Brasil, sobressai a atuação do Instituto Unibanco, Fundação Itaú Social, Fundação Lemann e Instituto Ayrton Senna que vem produzindo políticas e programas de educação básica para os sistemas públicos ${ }^{4}$.

A internacionalização das redes educacionais avançam tornando-se cada vez mais globais ao invés de locais ou nacionais (BALL, 2014) como é o caso da Rede Teach For All que opera no Brasil com o nome de Ensina Brasile recentemente firmou parceria com o estado do Mato Grosso.

\section{A recorrência de parcerias público-privadas no Sistema Estadual de Educação de Grosso e indicativos de hegemonia gerencialista em educação}

A oferta da educação no Estado de Mato Grosso dá-se pelas esferas pública e privada, em seus diferentes níveis e modalidades. Como assegura Cury $(2013)^{5}$, a esfera pública nunca representou ameaça ao setor privado no campo educacional, o que existe, desde as reformas gerenciais, são relações muito mais complexas entre o público e o privado, que têm alterado o conceito de educação e de escola públicas, ao introduzir um ethos do meio empresarial para o meio educacional. A educação é ofertada pela esfera pública - nas redes federal, estadual e municipal - e pela esfera privada em seus variados níveis e modalidades. A esfera pública estadual oferece à população educação em diferentes níveis, estando a Educação Básica (Ensino Fundamental e Ensino Médio) sob a responsabilidade da Secretaria de Estado de Educação (SEDUC) e a oferta do Ensino Superior e da Educação Profissional e Tecnológica sob a responsabilidade da Secretaria de Estado de Ciência e Tecnologia (SECITEC), por meio da Universidade do Estado de Mato Grosso (UNEMAT) e de escolas técnicas estaduais, respectivamente. 
Dados do Censo de 2014 apontam que a rede estadual é composta por 632 unidades escolares que trabalham, além do ensino regular, com modalidades diferenciadas, tais como: Educação Especial, Educação Indígena, Educação de Jovens e Adultos, Educação Profissional e Tecnológica/Nivel Médio e Educação do Campo. O número de alunos matriculados na rede em 2014, de acordo com o Censo Escolar, foi de 413.854 alunos (BRASIL, MEC/INEP, 2015). Desses, 72.617 frequentaram a primeira etapa do Ensino Fundamental regular.

O Sistema Estadual de Educação de Mato Grosso é composto pelo Conselho Estadual de Educação, o Fórum Estadual de Educação, a Secretaria de Estado de Educação e a rede de escolas públicas estaduais. Conforme organograma do órgão publicado no Decreto n 1106 , de 25 de abril de 2012, a SEDUC/MT está organizada em seis níveis, cada um com atuação específica na Educação Básica do Estado.

As ações da SEDUC nos municípios são intermediadas, principalmente, pelas Assessorias Pedagógicas e pelos Centros de Formação e Atualização dos Profissionais da Educação (CEFAPROS) (AMARAL, 2014). Há, no estado, 130 Assessorias Pedagógicas vinculadas à Superintendência de Gestão Escolar e 15 CEFAPROs ligados à Superintendência de Formação. Estes representam a SEDUC junto às escolas da rede pública estadual ou junto às Secretarias Municipais de Educação, quando há convênios entre municípios e estado. As Assessorias têm sob sua responsabilidade o monitoramento das políticas educacionais nas escolas estaduais, de cunho técnico e fortemente burocrático. Entre as funções desempenhadas por esse órgão, estão orientar, acompanhar e analisar a elaboração do Plano de Desenvolvimento Escolar (PDE), tendo por base instrumentos emanados do órgão central, e monitorar a execução do Plano de Desenvolvimento Escolar (PDE) nas unidades escolares mediante instrumentos avaliativos, emitidos pelo órgão central.

PDE pode ser considerado um dos primeiros casos de adoção de princípios do novo gerencialismo na educação pública de Mato Grosso, no final dos anos 1990, período marcado pelo alinhamento do governo Dante de Oliveira ao Governo Federal, ambos do PSDB. Ao mesmo tempo que o governo Dante de Oliveira adotava medidas de contenção de gastos por meio de política e da administração pública e da reforma fiscal, era aprovada a Lei n 7.040/1998 de Gestão Democrática do Ensino Público Estadual. 
Gerencialismo, Internacionalização da educação e o papel da Teach for all no Brasil

A aprovação dessa lei não serviu de constrangimento à adoção de políticas de cunho gerencialista na administração pública e na educação estadual. Oriundo de acordo entre o Ministério da Educação e Cultura e o Banco Mundial, o Programa Fundo de Fortalecimento da Escola (Fundescola)b ${ }^{6}$, criado em 1998, deu sustentação ao Plano de Desenvolvimento da Escola (PDE), seu principal projeto. Este se materializa por meio de planejamento estratégico gerencial, na busca da modernização da gestão e fortalecimento da autonomia escolar e de melhoria da qualidade do ensino (XAVIER; SOBRINHO, 1999).

$\bigcirc$ baixo desempenho dos estudantes mato-grossenses nos testes motivou o governo do estado (Blairo Maggi - 2003/2006-2007/2010) a buscar alternativas de melhoria dos resultados educacionais junto ao setor privado (AMARAL, 2014), resultando em duas parcerias entre 2006 e 2008: uma com a Fundação CESGRANRIO; a outra com o Instituto Ayrton Senna (IAS). Com a CESGRANRIO, adotou-se o projeto Eterno Aprendiz - Avaliação de alunos do Ensino Fundamental e capacitação docente de Língua Portuguesa e Matemática das escolas públicas estaduais, em 2006, e com o IAS, os Programas Se Liga e Acelera Brasil, em 2007, sendo implantado, em 2008, o Circuito Campeão, programa este de cunho preventivo, com estratégias de gerenciamento dos 260 resultados da aprendizagem. Com base nesse programa, foi implantado o Sistema Integrado de Gestão da Aprendizagem (SIGA), totalmente informatizado, com o objetivo de monitorar e acompanhar a aprendizagem de crianças do $1^{\circ}$ ciclo do Ensino Fundamental, nas áreas de Português e Matemática, em consonância com a matriz de referência da Provinha Brasil. A partir do fim de 2015, as iniciativas do governo estadual rumo à privatização da educação a partir da reforma educacional em curso foram intensificadas. Inicialmente, com a contratação do CAED - Centro de políticas públicas e avaliação da educação, da Universidade Federal de Juiz de Fora/MG, "uma instituição que operacionaliza (elabora e desenvolve) programas estaduais e municipais destinados a mensurar o rendimento de estudantes das escolas públicas", para a realização de uma Avaliação Diagnóstica do Ensino Público Estadual (ADEPE-MT), além das já existentes avaliações em larga escala sob a responsabilidade do governo federal. Em seguida, estabeleceu-se a parceria com a FALCONI (Consultores de resultados - empresa cujo objetivo é identificar problemas e causas e "transferir conhecimento gerencial com foco em resultados") e o Programa de Gestão para Resultados em Educação, com o propósito de formar diretores de escolas na perspectiva de "gestão de resultados" e também 
os professores formadores que atuam no CEFAPRO (Centro de Atualização e Formação dos Profissionais da Educação Básica).

Outra investida do governo se deu por meio da Portaria n 182/2016/ GS/SEDUC/MT, que instituiu uma Comissão Interna de estudo para análise e proposição de alteração da Lei n 7.040/98, que trata da gestão democrática das escolas em Mato Grosso. Como se não bastassem, as propostas de formação continuada que vinham se desenvolvendo nas escolas foram alteradas, não só no que diz respeito aos princípios que orientam os processos de formação docente, mas também em relação à organização do trabalho pedagógico restrito e amplo 8 . A recente contratação de serviços do Programa Ensina Brasil da Rede Teach For All é um forte indicativo das reais intenções do governo do estado com propostas fragmentadas de programas educacionais que, no seu conjunto, apontam para a privatização da educação pública.

\section{A Rede Teach For All, o Programa Ensina Brasil ou terceirizando a formação do professor}

A Teach For All, lançada em 2007, é uma rede global de mais de 40 organizações parceiras independentes pelo mundo, financiados localmente com uma visão compartilhada para criar oportunidades educacionais ampliada em seus países, segundo dados do site (TEACH FOR ALL,2017).

Cada organização recruta e desenvolve diversos futuros líderes para ensinar diferentes disciplinas em grandes salas de aula em busca de oportunidades expandidas para as crianças. Justificando que "[...] não há muito para aprender através das fronteiras". Teach For All tem uma abordagem global, ou seja, o mesmo programa é utilizado para diferentes contextos.

Nesse caso, a rede passa a atuar com os mesmos princípios: recrutamento, seleção e aplicação de conhecimentos práticos em parcerias com governos e instituições privadas com ênfase numa formação aligeirada de professores com caráter prático, do saber-fazer, deixando de lado a formação política-pedagógica, esvaziando o conteúdo da formação. Cria-se, assim, a indústria da formação aligeirada (FREITAS, 2016).

A Teach For All lança no mercado profissional da educação 8 a 10 mil professores por ano (FREITAS, 2016). É a internacionalização de uma ONG americana chamada Teach For América. Forma professores em cinco 
Gerencialismo, Internacionalização da educação e o papel da Teach for all no Brasil

semanas e é sustentada com dinheiro que inclui financiamento privado, oriundo de Fundações da Família Walton e de Bill Gates. É uma forma improvisada de aumentar os quadros de professores para atender à demanda por mais professores.

No Brasil, é caracterizada como uma Organização da Sociedade Civil de Interesse Público-OSCIP, entidade privada que pode receber recursos do Estado e de instituições privadas e se chama Ensina Brasil. Se apresenta como uma organização 100\% brasileira, independente e sem fins lucrativos e é mantido através de doações que recebe de seus parceiros.

Conforme o programa, o objetivo da rede é a troca de experiência e compartilhamento de conhecimentos e metodologias entre organizações que adotam esse mesmo programa ao redor do mundo. A instituição trabalha para expandir oportunidades educacionais acelerando o impacto das organizações que formam a rede, compartilhando aprendizados e informações, de modo a gerar sinergias que ajudem a superar os desafios e maximizar os impactos (CAETANO, 2018). Concorda-se com Ball (2014, p. 123) que chama de "[...] soluções rápidas para problemas difíceis". Segundo o autor, as soluções rápidas têm três componentes: são técnicas (utilizam uma única e nova tecnolo262 gia), são genéricas (aplicáveis independente da diversidade e contexto locais), podem ampliar-se (do âmbito local, nacional e internacional). Esses componentes são encontrados na Teach for All como uma rede internacional de formação de professores e que abriga o Ensina Brasil.

Fazem parte dos parceiros institucionais a Fundação Estudar, a Bain\&Company, Brasil Cursinhos, Brasil Jr, MGov e AIESEC (Association Internationale des Estudiants en Sciences Economiques et Commerciales) e FEJESP. Como apoiadores institucionais: Instituto Sonho Grande, Instituto Samuel Klein, Fundação Arymax, Omidyar Network, Garcia Family Foudation, Grupo Sinergisa, The Haddad Foudation, Instituto Península, Fundação Lemann, Fundação Itaú Social. Esses últimos atuam, também, na Reforma do Ensino Médio, direcionando a política e fornecendo soluções para os problemas educacionais. Desse grupo de organizações apresentadas, muitas delas estão voltadas à formação da juventude através do empreendedorismo e do desenvolvimento de lideranças e fazem parte de redes globais ligadas à filantropia empresarial. 
Vale destacar que o programa se apresenta com o discurso da inovação e liderança dos professores, conceito muito utilizado e valorizado nas reformas educacionais pelos empresários.

No Brasil e no mundo, os parceiros também têm em comum três características no desenho organizacional que são fundamentais para o sucesso do modelo e da missão:

Operar empresa sem fins lucrativos empenhada em trabalhar a nível nacional, inovando e adaptando a abordagem ao contexto local; manter a independência do controle do governo e outras entidades externas, com uma placa autônoma, uma base de financiamento diversificada, e a liberdade para tomar decisões operacionais, desafiar paradigmas tradicionais e sustentar a abordagem em face da mudança externa; parcerias com os setores público e privado para garantir as colocações de ensino, financiamento e ambiente político favorável necessárias para atingir a missão compartilhada e sustentar impacto ao longo do tempo; assegurar a representação e inclusão de diversos membros da equipe, os participantes, alunos, e os suportes, com um foco sobre aqueles que compartilham o futuro de seus alunos (TEACH FOR ALL, 2017).

Vale salientar o interesse de grupos financeiros e filantropos, interessados em promover iniciativas na educação e na formação de professores em âmbito nacional e global com a incorporação da educação pública a uma lógica empresarial contemporânea, ou seja, a educação passa a integrar o setor de serviço e a escola é vista como empresa. E uma empresa visa lucros, resultados que devem ser medidos. Portanto, seria transpor à educação pública uma ideologia de produtividade e controle de qualidade, como preconiza a Teoria de Administração da Qualidade Total, especialmente relacionada ao trabalho do professor. Ademais, leva as reformas neoliberais globais a diferentes países, construindo uma hegemonia sobre a política e o conteúdo educacional.

Ensina Brasil opera no recrutamento e na seleção de jovens talentos, de diversas carreiras, formação inicial voltada ao desenvolvimento de práticas para a sala de aula e habilidades de liderança (humildade, resiliência, liderança, motivação, resolução de problemas, entre outros); alocação por dois anos como professor remunerado de escola pública em período integral, lecionando alguma matéria relacionada à sua graduação e formação contínua 
Gerencialismo, Internacionalização da educação e o papel da Teach for all no Brasil

ao longo dos dois anos do programa com acompanhamento constante de tutores e mentoria de professores veteranos e profissionais de diversas áreas. Segundo o site (http:/ /ensinabrasil.org/sejaumensina), para ser um "Ensina", é necessário ser um profissional comprometido, trabalhando em diferentes áreas e iniciativas, para que uma mudança sistêmica ocorra. O Programa busca jovens talentos de diversas carreiras que almejam trabalhar com um propósito e queiram direcionar seus talentos e esforços para os problemas mais complexos do país.

Para Souza e Sarti (2014), as principais habilidades desenvolvidas para a preparação desse novo professor têm assumido lugar de destaque no mercado formativo docente. As questões pedagógicas que ampliam a visão de mundo do professor em formação são relegadas a um segundo plano.

A invenção de um novo professor visa atender às exigências atuais de um país que vem sofrendo transformações bastante significativas na área educacional, em conformidade com a hegemonia do capital financeiro global, portanto, em um momento de intensa correlação de forças entre capital e trabatho de disputa por projetos antagônicos.

Entre os estados brasileiros a implantar o programa, encontram-se Mato Grosso, Mato Grosso do Sul e muito recentemente o estado do Espírito Santo. Nesse penúltimo, o Programa foi instituído, em 2017, pela Rede Estadual de Ensino, por meio do Decreto n 14.602 (31 de outubro de 2016), e implantado no ensino fundamental e médio de sete escolas estaduais de Campo Grande que aderiram ao programa.

O Secretário de Estado de Educação de Mato Grosso, Marco Marrafon, concedeu entrevista ao Mídia News em 18 de junho de 2017 quando informou a origem da parceria com a Teach For All: "O nosso caso específico a gente trouxe via o Consórcio Brasil Central lassociação pública formada por cinco Estados do Norte, Centro-Oeste e o Distrito Federal que atua em várias áreas). No estado de Mato Grosso, o Programa foi instituído também em 2017, por meio de Acordo de Cooperação nº 0367/2016 10 de maio de 2016 ), firmado entre a Secretaria de Estado de Educação (SEDUC) e a ENSINA.BR, com vigência até 10 de maio de 2019, cujo objeto refere-se

[... a inovação da área de educação do Estado, por meio da conjugação de esforços entre os partícipes visando o desenvolvimento de programa de incentivo à docência e à inovação metodológica 
no ensino básico estadual, no modelo Teach For All (ACORDO DE COOPERAÇÃO, 2016, p.31.

Posteriormente, o Estado publicou edital para seleção dos "Ensina". Foram selecionados 35 recém-formados de universidades brasileiras, distribuídos em 10 escolas da Rede Pública Estadual de Ensino, da capital Cuiabá e de Várzea Grande, situada na região metropolitana. Cada uma das escolas recebeu entre dois a três recém-formados para atuar nos anos finais do Ensino Fundamental e anos iniciais do Ensino Médio.

A implantação do Ensina Brasil em Mato Grosso não é unanimidade, bem como apresenta resistência dos professores. Conforme o Sindicato dos Professores do Estado (SINTEP),

A Secretaria de Estado de Educação vem interferindo de forma direta na gestão da escola. Primeiro foi a implantação pela via da coação do então diretor da escola para aceitar de forma unilateral e sem diálogo com a comunidade escolar, um projeto desenvolvido pela ONG Ensina Brasil, tido como de "inovação" pedagógica. A ONG Ensina Brasil se apresenta aos governos, como não tendo interesses financeiros, mas no fundo não tem é compromisso com a qualidade social da educação e se oferecem a implantar projetos ditos 'inovadores' com a contratação de profissionais não-docentes ou em formação, para atuar com salário e regime diferenciado de jornada na escola.Com a falsa realidade de que a experiência não tem custos para o Estado, a ONG Ensina Brasil é ligada a uma ONG dos Estados Unidos chamada Teacher For All (Professores para Todos), que pretende implantar nos sistemas públicos as práticas de flexibilização e minimização do Estado nas políticas públicas educacionais (SINTEPVG, 2017).

Diversos foram os movimentos realizados pelo Sindicato dos Professores em oposição à implantação do programa e a todas as demais formas de privatização adotadas pelo governo do estado do Mato Grosso como a terceirização, diminuição dos repasses às escolas, parcerias com o setor privado, conveniamentos que atacam de forma direta a gestão democrática, construída pelos professores ao longo de décadas, alterando a lógica de gestão e o direcionamento da política educacional. Como consequência, instala uma corporação internacional ligada à indústria de formação de professores. 
Com relação à duração do programa, o prazo de dois anos mostrou-se como o tempo mínimo para que o participante consiga assimilar o conteúdo das formações e aplicar esse conhecimento de forma efetiva em sala de aula, gerando o impacto desejado em seus alunos e consolidando, em si mesmo as habilidades necessárias para continuar impactando a sociedade ao sair do programa. Quanto ao salário, o participante é contratado diretamente pelos governos parceiros, podendo variar de acordo com a sua alocação no programa (ENSINA BRASIL, 2016).

financiamento do programa é arcado pelo Ensina Brasil, enquanto os salários dos participantes, pelos contratantes. No entanto essa forma de encaminhar as contratações e a formação dos professores pode ter repercussões para o trabalho docente por ser uma terceirização da formação docente. Não é necessário ter licenciatura para participar do programa.

Para Oliveira (2016, p. 1), que faz a crítica a essa proposta, iniciativas como essas "[...] produzirão profissionais que estarão em contato diário com jovens estudantes, mas que em nenhum momento de sua trajetória profissional aprofundaram uma reflexão sobre o ato de educar".

Para a autora, esses profissionais serão professores certificados para atuar com adolescentes mas sequer (re)conhecerão um debate qualificado sobre educação, fazendo de sua atuação "um bico". Hoje, estão aqui e amanhã ali, mas poderão participar dos projetos das escolas e decidir sobre a vida dos estudantes.

Coincidência, ou não, a recém-aprovada Lei n 13.415, de 16 de fevereiro de 2017, de (contra) reforma do Ensino Médio instituiu a figura do profissional com "notório saber" em substituição a um profissional da área, ou seja, sem a devida qualificação didático pedagógica e por área do conhecimento, para atuar na educação formal, de modo que essa proposta ressuscite o profissional leigo, que, por décadas atuou na área educacional e para cuja qualificação profissional governos das últimas décadas têm empreendido esforços. Tal reforma parece convergir para aquilo que propõe a formação no Teach For All, como alertou Freitas (2016). Nessa passagem, no site do programa deixa claro que

[...] a escolha de quais disciplinas devem ser lecionadas pelos participantes é feita pelo Ensina Brasil em conjunto com os governos parceiros e diretores das escolas, e leva em consideração 
as necessidades específicas de cada escola e da comunidade escolar. $\bigcirc$ participante irá lecionar uma matéria que tenha relação com a sua área de formação (por exemplo, engenheiros podem lecionar matemática e receberão a formação pedagógica e a licenciatura específica dessa disciplina). Durante o processo seletivo é possível ao candidato sinalizar a sua preferência. Faremos o possível para atender às solicitações, mas não há garantia de que elas serão concretizadas (ENSINA BRASIL, 2017).

risco dessa formação é de ser substituída pela certificação, além de permitir atrair profissionais de outras áreas para curtos períodos de exercício profissional, o que gera rotatividade na escola e o professor não cria vínculo com a escola, com os colegas e com os alunos, o que, atualmente, pode ser uma estratégia. Conforme Caetano (2018), o campo pedagógico é desvalorizado, bem como a profissionalização docente. Há uma tendência à desvalorização da categoria "professor" e considerando que a atual proposta de reforma do ensino médio propõe o notório saber em que as disciplinas que comporão o currículo poderão ser lecionadas por profissionais que não possuem formação adequada, mas "notório saber" na área onde atuarão, o resultado levará ao aprofundamento da precarização da educação e do trabatho docente (CAETANO, 2018).

Outra questão importante é que esse professor não tem estabilidade, uma vez que será subcontratado por tempo determinado, ou seja, será um professor terceirizado, sem vínculo e não sindicalizado (CAETANO, 2018). A tarefa de educar se define não pela identidade ou pertencimento a um grupo profissional, mas pelo seu interesse e dedicação declarados. Portanto, a desarticulação da categoria docente dificulta a representação e reivindicações coletivas.

Esse programa faz avançar o sistema de privatização da educação, especialmente numa área de grande importância no contexto educacional, a formação de professores. Desqualifica e desprofissionaliza o trabalho docente, defende o aligeiramento da formação, quando prioriza a formação continuada, em lugar da inicial, com um caráter eminentemente instrumental. Com o lançamento da atual política de formação de professores em 28 de fevereiro de 2018 pelo MEC, em que propõe projetos favorecendo a prática e desconsidera uma formação que privilegie a reflexão através de políticas públicas para tal, o Teach For all torna-se um programa que atende a esses interesses. 
Gerencialismo, Internacionalização da educação e o papel da Teach for all no Brasil

Nos Estados Unidos, o Relatório Teach For America: a Review of the evidence (2010) revela a falta de um impacto consistente do programa Teach For All. Também em artigo publicado por La Londe, Brewer \& Lubienski (2015), ressaltam a falta de dados mais concretos sobre o programa. O resumo abaixo é uma pequena mostra da atuação dessas organizações nos Estados Unidos há mais de duas décadas, sem, no entanto, resolverem os problemas por lá:

$\bigcirc$ que sabemos agora sobre a Teach For America (TFA): a base de pesquisa crescente sobre a TFA revela um cenário misto, mas também mostra que a defesa da TFA é enganosa (ver também 'três maiores mentiras'). Além disso, a TFA contribui negativamente para alguns problemas centrais que a educação pública enfrenta: evasão de professores; rotatividade do professor; e atribuição desigual de professores (alta pobreza e estudantes das minorias sendo atribuídos desproporcionalmente a professores novos e não certificados) (FREITAS, 2016).

Com as reformas educacionais em curso pelo mundo e através das pesquisas já realizadas (CAETANO, 2013; COSTA, 2011; PERONI, 2015), pode-se afirmar que o que está sendo disputado é o conteúdo da educação 268 pública brasileira, através do direcionamento da política de formação de professores, o que se vê, como exemplo, neste artigo.

Essas tendências influenciam as políticas educacionais especialmente na formação de professores e alteram o conteúdo da educação, da formação e das condições de contratação dos professores; das atividades das escolas no dia-a-dia e também a formação dos alunos. É o "professor mínimo" segundo Bochetti (2014, p. 186), modelo reproduzido em processos simplificados de ação sobre si mesmo que no, atual contexto político, histórico, econômico e social, começa a tomar corpo, através do discurso de inovação na escola e na sala de aula, atrelada à ideia de ativismo, praticismo e utilitarismo.

\section{Considerações Finais}

$\bigcirc$ presente artigo teve por objetivo analisar os avanços da privatização da política educacional na proposta de formação de professores através da ONG "Ensina Brasil" na educação pública, em especial, na rede estadual de ensino de Mato Grosso, a partir de 2015. 
Na rede estadual de ensino de Mato Grosso, percebe-se a alteração no Sistema Estadual de Ensino, influenciada pela égide do novo gerencialismo, analisado a partir de políticas, estratégias e alterações na legislação governamental implementadas por governos das últimas décadas do século XX e do presente século. Destaca-se, especialmente, as parcerias público - privadas entre o poder público estadual, entidades e fundações do terceiro setor mercantil com atuação em várias esferas de governos no país, culminando com as mais recentes incursões de parcerias com uma rede global, a Teach For All que opera no Brasil como Ensina Brasil que traz consequências para a formação de professores, alterando a cultura educacional.

Em relação ao Ensina Brasil, ele opera como formador de professores para as redes públicas de ensino com uma proposta questionável quanto à forma de encaminhar as contratações e o conteúdo da formação dos professores que pode ter repercussões para o trabalho docente.

$\bigcirc$ papel do professor passa a ser ressignificado, com uma proposta de formação utilitarista, em que a teoria é dissociada da prática. Nessa proposta de formação, o saber fazer torna-se a competência mais importante para o professor, uma vez que a formação não propõe uma reflexão teórica que aprofunde o papel deste. Esse tipo de formação passa a ser do interesse das empresas e dos estados nesse momento particular, quando a aplicação prática está descolada das reflexões políticas e filosóficas, uma espécie de treinamento no modelo empresarial sob a proposta de inovação.

Também faz parte desse processo a alteração da lógica de gestão, de democrática para gerencial, que é o componente-chave da maioria das versões de privatização, ameaçando alterar tanto as formas quanto o conteúdo do trabalho na escola, atingindo diretamente a relação estabelecida entre a escola, professores, alunos e comunidade.

Ao recuperar aspectos da atuação da Teach For All em países como os Estados Unidos, mostram-se os resultados pífios de sua atuação e que passam a ser modelo para o caso brasileiro. As investidas dos empresários, na educação, têm servido de orientação à formação docente no país, banalizando a profissão docente no contexto de duras investidas contra as políticas públicas, em especial os professores de escolas públicas, modificando o conteúdo da formação e as formas de atuação. 
Gerencialismo, Internacionalização da educação e o papel da Teach for all no Brasil

A educação deixa de ser um direito e torna-se objeto um negócio; alteram-se o conteúdo da educação e o lócus da formação docente; substitui-se o princípio democrático de autodeterminação didático-pedagógica e de organização e gestão da escola pública por orientações mercadológicas nas quais a educação pública integra o setor de serviços, constituindo-se mais um produto com valor de troca no mercado. Concluí-se, evidenciando, no artigo, como as instituições privadas organizadas em rede, vêm orientando as políticas educacionais em curso no país trazendo consequências para a gestão democrática da educação.

Essa forma peculiar de relação entre o público e o privado, a partir de parcerias, terceirização ou outras formas de gestão, opera com a instalação de ferramentas de mercado no próprio funcionamento da política pública e da escola. $\bigcirc$ programa Ensina Brasil, com a proposta de atuar nas redes públicas, precariza e desprofissionaliza o trabalho do professor.

\section{Notas}

$270 \quad 1$ A Presidente Dilma Vana Rousseff foi destituída do cargo por meio de um "[...] processo de impeachment" em 31 de agosto de 2016, compreendido por Noam Chomsky como um golpe brando (ARAUJO, 2016). O interesse desses atores é em implementar uma agenda ultra liberal e conservadora no pais de modo a neutralizar iniciativas, tanto político partidária à esquerda quanto os movimentos sociais populares.

2 A América Latina após a eleição de presidentes de orientação de centro-esquerda buscaram implementar agendas desenvolvimentistas e estariam vivenciando a construção - ao menos no plano retórico e de formulação de políicas interna e externa - de um novo modelo ou ideal de Estado, que concentra os discursos contrários aos ideais neoliberais e propõe novas perspectivas acerca do desenvolvimento e, consequentemente, do papel do Estado. A referida corrente de pensamento é denominada de neodesenvolvimentista ou novo-desenvolvimentista.

3 Nome atribuído aos estudantes que atuam no âmbito da ONG Teach For All.

4 Ver Peroni $(2013,2015)$.

5 Disponível em: http://www.anped.org.br/.../videos-conferencia-livre-sistema-nacional-de-educacao-e-a-conae-2014-6-de-maio-de-2013. Acesso em: 29 set. 2014.

6 O Programa destina-se às regiões mais pobres do Brasil (Norte, Nordeste e Centro-Oeste) e, dentro destas, às microrregiões mais populosas, definidas pelo Instituto Brasileiro de Geografia e Estatística (IBGE) (FONSECA, 2003).

7 A parceria com a SEDUC/MT teve início em 2006, com o objetivo de avaliar os mais de 300 mil alunos do Ensino Fundamental das escolas estaduais nas disciplinas de Matemática e Língua Portuguesa e capacitar 5.800 professores efetivos em exercício das respectivas disciplinas, visando a reverter os indicadores (AMARAL, 2014). 
8 De acordo com Freitas (2008, p. 86) a organização do trabalho pedagógico pode ser entendida em dois níveis: "a) como trabalho que, no presente momento histórico, costuma desenvolver-se predominantemente em sala de aula; e b) como organização global do trabalho pedagógico na escola, enquanto projeto políitico pedagógico da escola."

\section{Referências}

AMARAL, Maria Clara Ede. Relações público-privado na Educação de Mato Grosso. 2014. 220f. Tese (Doutorado em Educação) - Programa de Pós-graduação em Educação, Universidade de Campinas, Campinas, 2014.

ANTUNES, Fátima. A nova ordem educacional. Espaço europeu de educação e aprendizagem ao longo da vida. Coimbra: Almedina, 2008.

ARAÚJO, Carla. Linguista Noam Chomsky defende Dilma e diz que ela é acusada por 'gangue de corruptos'. O Estado de São Paulo, São Paulo, 18 maio 2016. Disponível em: Politica.estadao.com.br. Acesso em: 16 set. 2017.

BAlL, Stephen. Performatividade, privatização e Pós-Estado do Bem-Estar. Educação \& Sociedade, Campinas, v. 25, n. 89, p. 1 105-1126, set./dez. 2004.

BALL, Stephen; YOUDELL, Deborah. Hidden privatization in public education. Preliminary

Report, Education International 5th World Congress. Institute of Education, University of London, july, 2007.

BALL. Stephen. Educação global S.A. Novas redes políticas e o imaginário neoliberal. Ponta Grossa: UEPG, 2014.

BALL, Stephen; JUNEMANN, Carolina. Networks, new governance and education. Bristol: Policy Press, 2012.

BALL, Stephen; OLMEDO, Antônio. A nova filantropia, o capitalismo social e as redes de políticas globais em educação. In: PERONI, Vera Maria Vidal (Org.). Redefinições das fronteiras entre o público e o privado: implicações para a democratização da educação. Brasília: Líber Livro, 2013.

BOCCHETTI, André. Um governo máximo, um professor mínimo: tecnologias de produção docente em programas especiais de formação. In: SOUZA. Denise Trento Rebello de. SARTI. Flavia Medeiros(Org.). Mercado de formação docente. Belo Horizonte: Fino Traço, 2014

BRASIL. Presidência da República. Ministério da Administração e Reforma do Estado (MARE). Plano Diretor da Reforma do Aparelho de Estado. Brasília: 1995. 
Gerencialismo, Internacionalização da educação e o papel da Teach for all no Brasil

BRASIL. Ministério da Educação. Instituto Nacional de Estudos e Pesquisas Educacionais Anísio Teixeira: Censo Escolar 2014. Brasília-DF, 2015.

CAETANO, Maria Raquel. Relações entre o público e o privado: a gestão pedagógica da educação no Programa Circuito Campeão do Instituto Ayrton Senna (2007-2010). 2013, 301 p. Tese (Doutorado em Educação) - Programa de Pós-graduação em Educação. Universidade Federal do Rio Grande do Sul, Porto Alegre, 2013.

CAETANO, Maria Raquel. Lógica privada na educação pública, redes globais e a formação de professores. Revista Eletrônica de Educação, São Carlos, v. 12, n. 1, p. 120-131, jan./abr. 2018.

CAETANO, Maria Raquel; PERONI, Vera Maria Vidal. Ensino médio no Brasil e a proposta educacional do Instituto Unibanco: considerações sobre a mercantilização da educação pública. In: PERONI, Vera Maria Vidal (Org.). Diálogos sobre as redefinições do papel do Estado e sobre as fronteiras entre o público e o privado. São Leopoldo: Oikos, 2015.

CLARKE, John; NEWMAN, Janet. The Managerial State: power, politics and ideology in the remaking of Social Welfare. London: Sage Publications, 1997.

COSTA, Marilda de Oliveira. Concepções de gestão nos Programas do Instituto Ayrton

272 Senna no contexto de alterações no papel do Estado e da sociedade. 201 1, 353f. Tese (Doutorado em Educação) - Programa de Pós-Graduação em Educação, Universidade Federal do Rio Grande do Sul, Porto Alegre, 2011.

CURY, Carlos Roberto Jamil. $\bigcirc$ direito de aprender: base do direito à Educação. In: ABMP - Todos pela Educação. Justiça pela qualidade na educação. São Paulo: Saraiva, 2013.

DALE, Roger. Globalização e educação: demonstrando a existência de uma "Cultura Educacional Mundial Comum" ou localizando uma Agenda Globalmente Estruturada para a Educação" ? Educação \& Sociedade, Campinas, v. 25, n. 87, p. 423-460, maio/ago. 2004.

ENSINA BRASIL. Seja um ensina (2016). Disponível em: http://ensinabrasil.org/sejaumensina Acesso em: 12. jul. 2016

ENSINA BRASIL. Perguntas frequentes. Quais disciplinas posso ensinar? É possível escoIher? (2017) Disponível em: https://www.ensinabrasil.org/perguntasfrequentes. Acesso em: 7 jul. 2017.

FAGNANI. Eduardo. O fim do breve ciclo da cidadania social no Brasil (1988-2015). Texto para Discussão. Unicamp. IE, Campinas, n. 308, jun. 2017. 
FREITAS, Luís Carlos de. Notório saber.2016. Vire professor em cinco semanas. Disponível em: https://avaliacaoeducacional.com/2016/.../notorio-saber-vire-professor-em-5-semanas. Acesso em: 12 ago. 2017.

GIDDENS, Anthony. A terceira via. Reflexões sobre o impasse político atual e o futuro da social democracia. Rio de Janeiro: Record, 2001.

LIMA, Licínio Carlos. Apresentação Dossiê - Privatização da educação no contexto da(s) "Terceira(s) Via(s)": uma caracterização em análise. Currículo Sem Fronteiras, v. 13, n. 2, p. 177-181, maio/ago. 2013.

MATO GROSSO. Lei $\mathbf{n}^{\circ} \mathbf{7} . \mathbf{0 4 0}$, de $\mathbf{1}^{\circ}$ de outubro de 1998. Dispõe sobre a regulamentação do Art. 14 da Lei federal n 9394, de 20 de dezembro de 1996 bem como o inciso VI do Art. 2006 da Constituição Federal, que estabelecem Gestão Democrática do Ensino Público Estadual, adotando Sistema seletivo para a escolha de dirigentes dos estabelecimentos de ensino e a criação dos conselhos Deliberativos da Comunidade Escolar nas Unidades de Ensino. Mato Grosso, 1998.

MATO GROSSO. Decreto $\mathbf{n}^{\circ} \mathbf{1}$ 106, de 25 de abril de 2012. Dispõe sobre a Organização Administrativa da Secretaria de Estado de Educação e Cultura. SEDUC/MT. Mato Grosso, 2012.

MATO GROSSO. Acordo de Cooperação n ${ }^{\circ}$. 0367/2016, de 10 de maio de 2016, firmado entre a Secretaria de Estado de Educação (SEDUC) e a ENSINA.BR, com vigência até 10 de maio de 2019. Mato Grosso, 2016.

MATO GROSSO. Portaria $\mathbf{n}^{\circ}$ 182/2016/GS/SEDUC/MT. Institui a comissão interna de estudo para análise e proposição de alteração da Lei n 7.040/98. Mato Grosso,2016.

MÉSZÁROS, Istvan. Para além do capital. São Paulo: Boitempo. 2002.

A crise estrutural do capital. Tradução Francisco Raul Cornejo e outros. São Paulo: Boitempo, 2009.

MÍDIA NEWS. MT implanta programa inspirado em modelo norte-americano. Entrevista a Karina Cabral em 18.jun. 2017. Disponível em:<http://www.midianews.com.br/cotidiano/mt-implanta-programa-inspirado-em-modelo-norte-americano/2989440> Acesso em: 10 ago. 2017.

MONTAÑO, Carlos. Terceiro Setor e Questão Social: crítica ao padrão emergente de intervenção social. São Paulo: Cortez, 2002. 
Gerencialismo, Internacionalização da educação e o papel da Teach for all no Brasil

NEWMAN, Janet; CLARKE, John. Gerencialismo. Educação e Realidade, Porto Alegre, v. 37, n. 2, p. 353-381, maio/ago. 2012.

OFFE, Claus. Problemas estruturais do Estado capitalista. Tradução Barbara Freitag. Rio de Janeiro: Tempo Brasileiro, 1984.

OLIVEIRA, Natália Braga de. Reforma do ensino médio, gênero e desvalorização do magistério. Disponível em: http://blogjunho.com.br/reforma-do-ensino-medio-genero-e-desvalorizacao-do-magisterio/. 29 set. 2016 . Acesso em: 2 out. 2016.

PERONI, Vera Maria Vidal. Reforma do Estado e a tensão entre o público e o privado. Revista SIMPE-RS, Porto Alegre, p. 11 - 33, 15 abr. 2007.

PERONI, Vera Maria Vidal. A relação público/privado e a gestão da educação em tempos de redefinição do papel do Estado. In: ADRIÃO, Theresa; PERONI, Vera. (Org.). Público e - Privado na Educação: novos elementos para o debate. 1ed.São Paulo: Xamã, 2008, v. 01, p. $111-127$.

PERONI, Vera Maria Vidal (Org.). Redefinições das fronteiras entre o público e o privado: implicações para a democratização da educação. Brasília: Liber Livro, 2013.

PERONI, Vera Maria Vidal. Implicações da relação público-privada para a democratização da educação no Brasil. In: PERONI, Vera Maria Vidal (Org.). Diálogos sobre as redefinições do papel do Estado e sobre as fronteiras entre o público e o privado. São Leopoldo: Oikos, 2015.

PORTER, Michael Eugene. A vantagem competitiva das nações. Tradução de Waltensir Dutra. Rio de Janeiro: Campus, 1993.

SOUZA, Denise Trento Rebello de; SARTI, Flávia Medeiros. Mercado simbólico de formação docente. In: SOUZA, Denise Trento Rebello de; SARTI, Flávia Medeiros. Mercado de formação docente. Belo Horizonte: Fino Traço, 2014.

SMITH, William C. The global testing culture shaping education policy, perceptions, and practice. Edited by WILLIAM C. SMITH, 2016.

SINDICATO dos Professores do Estado do Mato Grosso-Várzea Grande(SINTEPVG). Escola Estadual Garcia Neto em Várzea Grande suspende aulas por 3 dias para exigir ação da SEDUC. Disponível em: http://www.sintepvg.org/noticias/id-624857/escola_estadual_ garcia_neto_em_vg_suspende_aulas_por_3_dias_para_exigir_acao_da_seduc. Acesso em: 2 ago. 2017. 
TEACH FOR ALL. Disponivel em: http://teachforall.org/en/our-network-and-impact/network-partners. Acesso em: 2 out. 2017.

XAVIER, Antônio Carlos; AMARAL SOBRINHO, José. Como elaborar o Plano de Desenvolvimento da Escola, aumentando o desempenho da escola por meio do planejamento eficaz. 2. ed. Brasília: Programa FUNDESCOLA, 1999.

Prof ${ }^{a}$. Dr ${ }^{a}$. Maria Raquel Caetano Instituto Federal de Educação, Ciência e Tecnologia Sul-Rio-Grandense | Campus Sapucaia do Sul Programa de Pós-Graduação em Educação Profissional e Tecnológica Grupo de Pesquisa "Implicações da relação público-privada para a democratização da educação na América Latina: Uruguai, Argentina, Venezuela, Chile, Bolívia e Brasil" | UFRGS E-mail | caetanoraquel2013@gmail.com

Profa. Dra. Marilda de Oliveira Costa Universidade do Estado de Mato Grosso | Cáceres- Mato Grosso Faculdade de Educação e Linguagem

Programa de Pós-graduação em Educação Grupo de Pesquisa Juventude, Cultura e Políticas Públicas Coordena a Pesquisa "Análise do Sistema Integrado de Gestão da Aprendizagem da Secretaria de Estado de Educação de Mato Grosso e suas implicações para a gestão e o desempenho escolar pedagógico" E-mail | marildacosta@hotmail.com

Recebido 3 maio 2018 Aceito 4 jun. 2018 